\title{
INCIDENCE OF FAILED EPIDURAL ANAESTHESIA FOR EMERGENCY CESAREAN SECTION AND CONVERSION RATE TO SPINAL OR GENERAL ANAESTHESIA
}

\author{
Authors: Lal S', Narayanan $\mathbf{N}^{2}$, Thomas J', Singh $\mathbf{V}^{2}$
}

Department of Anesthesiology and Critical Care Our Lady of Lourdes Hospital, Drogheda, Ireland

I registrar 2 consultant

\section{Background and Aims:}

Recent advances in labour analgesia reflect high quality of care. It's not just a focus on pain relief but an overall quality of care of patients in labour. The overall incidence of epidural failure is reported as $23 \%$ in a teaching institution but Royal College of Anaesthetists suggests that the incidence of General Anaesthesia (G.A) in a parturient with a labour epidural analgesia should not more than 3\%. The main objective of this study was to find out the number of the patients on epidural analgesia requiring conversion of epidural anaesthesia to spinal or G.A for emergency caesarean sections.

\section{Methodology:}

Study was conducted at Our lady of Lourdes Hospital, Drogheda over 2 months after the approval of local audit committee. All Patients coming for emergency $\mathrm{C}$ section (not Category I) on Epidural analgesia were included. We collected retrospective data from 08 May 2018 to 07 May 2019.

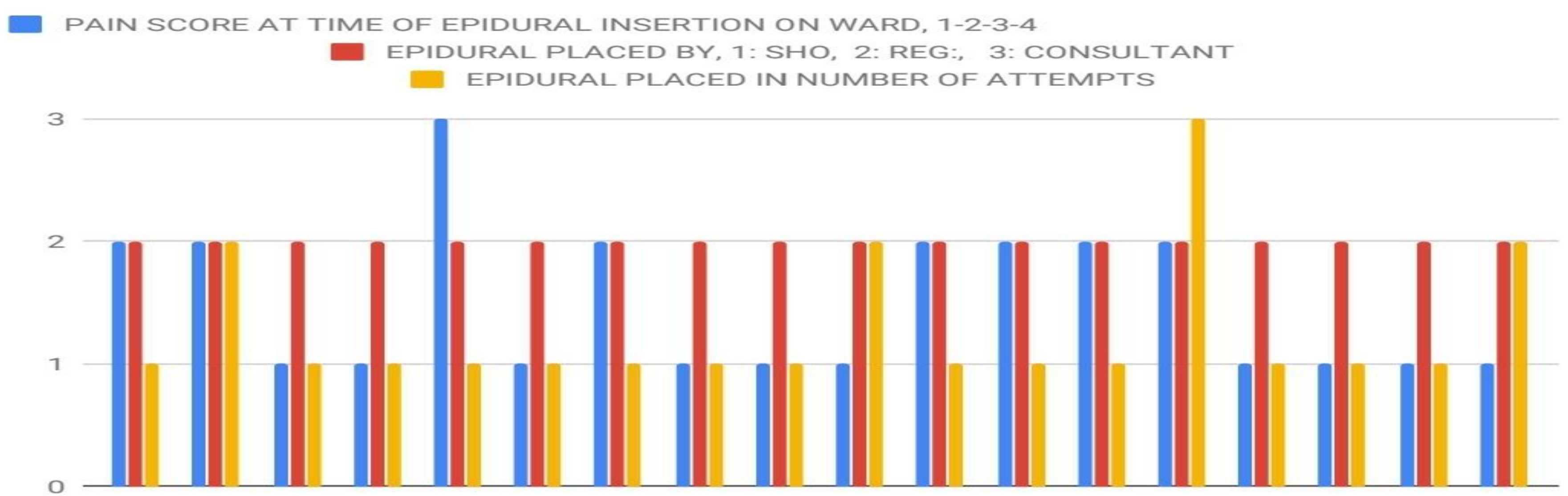

\section{Result:}

Total number of cases came to operation theatre with epidural in situ for emergency caesarean section was 229. Out of which 18 cases converted into general anaesthesia and 3 cases into spinal anaesthesia. Various factors were noted for failure. The two main reasons for failure of epidural anaesthesia were inadequate epidural analgesia in labour ward and top up with different volumes.

\section{IN CASE OF C-SECTION, EPIDURAL CONVERTED TO I: SPINAL ANAESTHESIA, 2: GENERAL ANAESTHESIA}

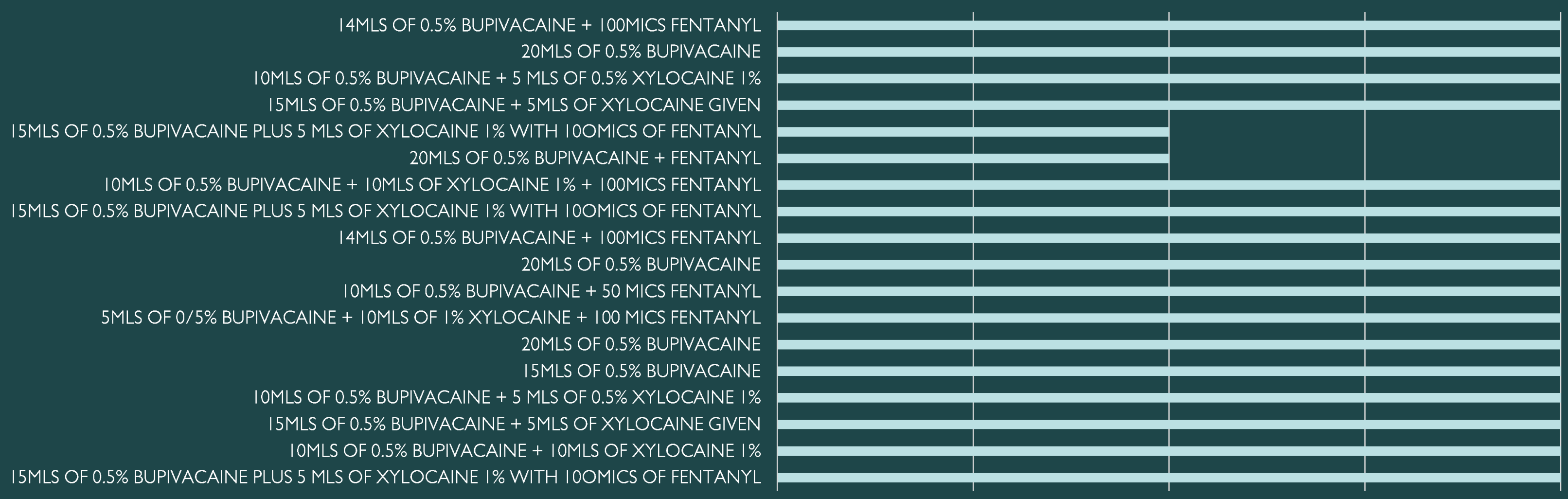

\section{Conclusion:}

In our audit, we found that $7.8 \%$ incidence of conversion in GA in a parturient's with epidural in situ, which is high as compared to Royal College of Anaesthetists guideline. Uniformity among the clinician's method in topping up the epidural and early recognition of inadequate epidural analgesia in the labour ward which needed to be rectified (re-insertion of epidural catheter). 